URBAN, Renan Lucas Dutra. Decisões técnicas, escolhas morais e democracia: agências reguladoras e deliberação sobre direitos fundamentais. Revista Eletrônica Direito e Política, Programa de PósGraduação Stricto Sensu em Ciência Jurídica da UNIVALI, Itajaí, v.13, n.2, $2^{\circ}$ quadrimestre de 2018. Disponível em: www.univali.br/direitoepolitica - ISSN 1980-7791

\title{
DECISÕES TÉCNICAS, ESCOLHAS MORAIS E DEMOCRACIA: AGÊNCIAS REGULADORAS E DELIBERAÇÃO SOBRE DIREITOS FUNDAMENTAIS ${ }^{1}$
}

\author{
TECHNICAL DECISIONS, MORAL CHOICES AND DEMOCRACY: REGULATORY \\ AGENCIES AND DELIBERATION ON FUNDAMENTAL RIGHTS
}

Renan Lucas Dutra Urban²

SUMÁRIO: Introdução; 1 Delegação legislativa e custos; 20 problema do controle dos atos regulatórios tecnicamente complexos; $3 \mathrm{~A}$ burocracia reguladora como fórum de deliberação sobre direitos fundamentais; Considerações Finais; Referência das fontes citadas.

\begin{abstract}
RESUMO
É um equívoco considerar que as agências reguladoras independentes tomam decisões com base exclusivamente em questões técnicas. Elas também decidem problemas de moralidade política, interferindo diretamente na esfera dos direitos dos indivíduos. Nesse contexto, qual é a legitimidade das agências reguladoras, enquanto corpos não majoritários, para editar normas jurídicas gerais e abstratas? A doutrina tradicional defende um controle judicial e político do poder normativo das agências reguladoras como solução para o problema do déficit democrático. Contudo, a falta de capacidade técnica específica das instituições responsáveis por esse controle tem de ser levada a sério. Neste artigo, faz-se uma defesa substantiva da legitimidade democrática da atividade normativa regulatória. Nos termos da tese aqui sustentada, as agências reguladoras são tanto mais legítimas para editar normas jurídicas - e, por conseguinte, para promover e restringir direitos dos administrados - quanto maior for a qualidade ou eficiência de suas decisões.
\end{abstract}

Palavras-chave: agências reguladoras; poder normativo; delegação legislativa; legitimidade democrática.

\footnotetext{
1 O presente texto é semelhante ao apresentado, sob o mesmo título, ao I Simpósio de Pesquisa em Direito da USP/Faculdade de Direito de Ribeirão Preto e, sob o título "Agências reguladoras, capacidades institucionais e democracia", ao XVII Encontro de Pesquisadores da Uni-FACEF. O artigo encaminhado para publicação neste periódico, no entanto, reflete um estágio mais avançado da pesquisa, na medida em que incorpora novas reflexões do autor sobre o tema. De fato, em comparação com o texto dos artigos apresentados no âmbito dos referidos eventos acadêmicos, o texto do artigo ora enviado para publicação pela "Revista Eletrônica Direito e Política" apresenta novidades importantes, tendo sido seus itens 2 ("O problema do controle dos atos regulatórios tecnicamente complexos") e 3 ("A burocracia reguladora como fórum de deliberação sobre direitos fundamentais") completamente reformulados. Assim, embora semelhantes em alguns trechos, tais textos apresentam desenvolvimento e conclusões substancialmente diversas, o que é suficiente para caracterizar a originalidade e o ineditismo exigidos para a publicação do presente artigo.

2 Mestre em Direito pela Universidade Estadual Paulista "Júlio de Mesquita Filho", Faculdade de Ciências Humanas e Sociais (UNESP, Campus de Franca), e graduado em Direito pela mesma instituição. Franca - São Paulo - Brasil. E-mail: renanurban@hotmail.com.
} 
URBAN, Renan Lucas Dutra. Decisões técnicas, escolhas morais e democracia: agências reguladoras e deliberação sobre direitos fundamentais. Revista Eletrônica Direito e Política, Programa de PósGraduação Stricto Sensu em Ciência Jurídica da UNIVALI, Itajaí, v.13, n.2, $2^{\circ}$ quadrimestre de 2018. Disponível em: www.univali.br/direitoepolitica - ISSN 1980-7791

\section{ABSTRACT}

It is a mistake to consider that regulatory independent agencies take decisions based exclusively on technical issues. They also decide political morality problems, interfering directly in the sphere of fundamental rights. In this context, what is the legitimacy of the independent agencies, as non-majoritarian bodies, to enact general and abstract legal norms? The traditional doctrine advocates a judicial and political control of agency rulemaking as a solution to the democratic deficit problem. However, the lack of specific capacity of the institutions responsible for this control should be taken seriously. This paper presents a substantive defense of the legitimacy of agency rulemaking. According to the thesis here advocated, independent agencies have legitimacy to edit legal norms - and therefore to promote and restrict fundamental rights - insofar as their decisions reach certain standard of quality or efficiency.

Keywords: independent agencies; agency rulemaking; legislative delegation; democratic legitimacy.

\section{INTRODUÇÃO}

A delegação de competência normativa às agências reguladoras implica atribuir a tais entes o poder de decidir não apenas questões factuais, mas também problemas de moralidade política. Esse ponto, apesar de subentendido na discussão sobre o déficit democrático das agências reguladoras - e de outras entidades administrativas, dotadas de poder normativo ${ }^{3}$ - não costuma ser explorado na literatura jurídica.

A afirmação de que a burocracia reguladora também faz escolhas morais fere a leitura tradicional da teoria da separação dos poderes, que não concebe a possibilidade de que outras instituições, senão as político-majoritárias, profiram decisões com conteúdo político. Além disso, destoa da corrente teórica que, ao idealizar as funções de fiscalização e de ordenação das agências, concebe-as como entes politicamente neutros, encarregados de emitir juízos tão somente técnicos acerca dos problemas relativos à regulação.

\footnotetext{
3 No Direito Público brasileiro, a delegação legislativa é objeto de discussão desde o período do Império. Os debates sobre o poder normativo de órgãos da Administração Pública, assim, não se circunscrevem às agências reguladoras, embora tenham se intensificado a partir da criação dessas entidades. Cf., a esse respeito, VEIGA DA ROCHA, Jean Paul Cabral. A capacidade normativa de conjuntura no direito econômico: o déficit democrático da regulação financeira. $204 \mathrm{f}$. Tese (Doutorado em Direito) - Faculdade de Direito, Universidade de São Paulo, São Paulo, 2004. p. 175195.
} 
URBAN, Renan Lucas Dutra. Decisões técnicas, escolhas morais e democracia: agências reguladoras e deliberação sobre direitos fundamentais. Revista Eletrônica Direito e Política, Programa de PósGraduação Stricto Sensu em Ciência Jurídica da UNIVALI, Itajaí, v.13, n.2, $2^{\circ}$ quadrimestre de 2018. Disponível em: www.univali.br/direitoepolitica - ISSN 1980-7791

O objetivo deste trabalho é discutir a possibilidade de que as agências reguladoras - corpos burocráticos não majoritários e pouco responsivos à opinião pública façam escolhas valorativas, no contexto do Estado Democrático de Direito. O presente estudo tem a seguinte estrutura. Na seção 1 , analisa-se a atribuição de competência normativa às agências reguladoras como um ato de delegação, ou decisão de segunda ordem. Nesse passo, analisa-se um primeiro problema relacionado à delegação: os custos associados à decisão final. A seção 2 aborda o tema do controle das normas editadas pelos entes de regulação. Com base na ideia de capacidade institucional relativa, discute-se, aqui, o problema da definição da intensidade do controle sobre a atividade normativa regulatória. Na seção 3, por fim, estuda-se a legitimidade democrática da burocracia reguladora para fazer escolhas morais. Nessa parte do trabalho, defende-se a ideia de que a legitimidade das agências reguladoras para deliberar sobre direitos fundamentais pode ser maior ou menor, conforme a qualidade das decisões por elas proferidas.

\section{DELEGAÇÃO LEGISLATIVA E CUSTOS}

As agências reguladoras independentes surgiram, no Brasil, ao longo da década de 90 , no contexto das reformas estruturais por que passou o Estado, visando ao fortalecimento de seu papel regulador da economia. Ao transferir a responsabilidade da provisão direta de determinados serviços de infraestrutura para o setor privado - por intermédio da alienação de empresas estatais e de concessões de serviços públicos - , o Estado brasileiro, seguindo a tendência observada, a partir dos anos 80, no Reino Unido, na Europa Ocidental, na Ásia e na América Latina, criou entes de regulação ou thes conferiu maior autonomia, reforçando os mecanismos de intervenção indireta no domínio econômico. ${ }^{4}$

Dotadas de autonomia decisória, as agências reguladoras exercem uma capacidade normativa de conjuntura, instrumental à sua tarefa de disciplinar atividades econômicas e serviços de relevante interesse social. Assim, paralelamente às instâncias legislativas, elas se apresentam como relevantes

${ }^{4}$ Cf. PRADO, Mariana Mota. Agências reguladoras, independência e desenho institucional. São Paulo: Bovespa, Duke Energy, Ipiranga e Instituto Tendências, 2005. p. 125. 
URBAN, Renan Lucas Dutra. Decisões técnicas, escolhas morais e democracia: agências reguladoras e deliberação sobre direitos fundamentais. Revista Eletrônica Direito e Política, Programa de PósGraduação Stricto Sensu em Ciência Jurídica da UNIVALI, Itajaí, v.13, n.2, $2^{\circ}$ quadrimestre de 2018. Disponível em: www.univali.br/direitoepolitica - ISSN 1980-7791

fóruns de decisão, expedindo normas que inovam a ordem jurídica e restringem diretamente os direitos dos administrados. ${ }^{5}$

A atribuição de competência normativa à burocracia reguladora pode ser vista como um ato de delegação, isto é, uma decisão de segunda ordem 6 por meio da qual uma instituição - o Poder Legislativo - busca minimizar os custos ${ }^{7}$ associados à resolução de problemas complexos, transferindo o ônus da decisão final para outra instituição - a agência de regulação -, idealmente capaz de oferecer melhores respostas para tais problemas.

Nesse sentido, pode-se dizer que a delegação de competência normativa às agências visa a um incremento de racionalidade e de eficiência na regulação, assentando-se, basicamente, em dois pressupostos: o de que o processo legislativo, em razão de seu tempo de maturação e da sua não especialização, é incapaz de atender às demandas conjunturais que emanam dos sistemas econômico e político-burocrático; e o de que as agências reguladoras, em função de sua autonomia reforçada e de sua expertise técnica, estão mais bem capacitadas para solucionar os problemas complexos relacionados a esses sistemas. $^{8}$

Em termos gerais, a delegação implica, à primeira vista, uma decisão de baixos custos tanto para o delegante - cujo trabalho consiste em exportar, para um

5 VEIGA DA ROCHA, Jean Paul Cabral. A capacidade normativa de conjuntura no direito econômico: o déficit democrático da regulação financeira. p. 29.

6 Decisões de segunda ordem são meta-decisões, isto é, decisões sobre como decidir. Como afirmam Sunstein e Ullmann-Margalit, tais decisões resultam do reconhecimento de dois fatos: o de que decisões de primeira ordem podem estar erradas e o de que alcançar decisões de primeira ordem corretas pode ser algo extremamente difícil ou custoso. Cf., no ponto, SUNSTEIN, Cass R.; ULLMANNMARGALIT, Edna. Second order decisions. John M. Olin Law \& Economics Working Paper, Chicago, n. 57, p. 14, 1998.

7 O termo "custos", aqui, remete aos limites dos aplicadores do direito para formular respostas apropriadas para problemas jurídicos em contextos reais de tomada de decisão. Abrange, dessa maneira, tanto os "custos de erro", relacionados ao número e à gravidade dos equívocos cometidos pelos órgãos julgadores, quanto os "custos de decisão", concernentes aos recursos escassos - como tempo, dinheiro e esforço mental - que tais órgãos têm de investir para a solução de determinado problema. Cf., sobre isso, SUNSTEIN, Cass R. Must formalism be defended empirically? The University of Chicago Law Review, Chicago, v. 66, n. 3, p. 647, Sum. 1999. Cf., também, SUNSTEIN, Cass R.; ULLMANN-MARGALIT, Edna. Second order decisions. p. 13-16.

8 Cf. LOPES, Othon de Azevedo. Princípios jurídicos e regulação. 251 f. Tese (Doutorado em Direito) - Pontifícia Universidade Católica de São Paulo, São Paulo, 2011. p. 236-237. 
URBAN, Renan Lucas Dutra. Decisões técnicas, escolhas morais e democracia: agências reguladoras e deliberação sobre direitos fundamentais. Revista Eletrônica Direito e Política, Programa de PósGraduação Stricto Sensu em Ciência Jurídica da UNIVALI, Itajaí, v.13, n.2, $2^{\circ}$ quadrimestre de 2018. Disponível em: www.univali.br/direitoepolitica - ISSN 1980-7791

terceiro, o ônus da decisão final - como para o delegado - em face de suas melhores condições para resolver certo problema. Nesse sentido, dado o binômio "ônus ex ante - ônus ex post", a delegação poderia ser classificada como um caso especial de estratégia de segunda ordem do tipo "baixo - baixo". 9 Mas, como toda estratégia decisória ou decisão de segunda ordem, a delegação também apresenta dificuldades.

A primeira dificuldade relacionada à delegação diz respeito aos custos da decisão final. O ônus de decidir determinado problema pode se mostrar extremamente pesado, à vista das limitações epistêmicas de quem recebe a delegação. Nesse caso, os custos associados à tomada de decisão se elevam, e a delegação se apresenta não como uma decisão de segunda ordem do tipo "baixo - baixo", mas do tipo "baixo - alto". ${ }^{10}$

O controle dos atos normativos regulatórios é a chave para a compreensão desse problema. As agências reguladoras não possuem a última palavra sobre os assuntos relativos à regulação. Como todo ato administrativo geral, os atos normativos regulatórios estão sujeitos a dois tipos de controle: o judicial e o político. ${ }^{11}$ O controle exercido pelo Poder Judiciário decorre da regra da inafastabilidade de jurisdição, prevista no artigo 50, inciso XXXV, da Constituição Federal. ${ }^{12}$ Já o controle político é exercido sobretudo pelo Poder Legislativo, de

\footnotetext{
9 SUNSTEIN, Cass R.; ULLMANN-MARGALIT, Edna. Second order decisions. p. 22.

10 SUNSTEIN, Cass R.; ULLMANN-MARGALIT, Edna. Second order decisions. p. 20.

11 Cf., nesse sentido, SUNDFELD, Carlos Ari. Introdução às agências reguladoras. In:

(coord). Direito administrativo econômico. São Paulo: Malheiros, 2002. p. 26. Outra forma de controle sobre os atos normativos regulatórios é aquela realizada por atores da sociedade civil, mediante participação nos procedimentos administrativos. As leis que criaram as agências reguladoras preveem diversos mecanismos de participação democrática, como as audiências públicas, as consultas públicas e os conselhos consultivos. Sem prejuízo da necessidade de aperfeiçoamento destes mecanismos, a fim de propiciar uma participação mais efetiva dos cidadãos, é certo que eles configuram um importante canal de comunicação entre os atores da sociedade civil e os agentes reguladores, permitindo, em maior ou menor medida, a influência direta daqueles na formação das decisões tomadas por estes. Para uma análise empírica do funcionamento dos mecanismos de participação pública no âmbito da Agência Nacional de Telecomunicações (ANATEL), cf. MATTOS, Paulo Todescan Lessa. O novo Estado regulador no Brasil: eficiência e legitimidade. São Paulo: Singular, 2006. p. 267-300. Sobre as consultas públicas e audiências públicas, cf., neste trabalho, seção 3.

12 Cf. BRASIL. Constituição (1988). Constituição da República Federativa do Brasil de 1988. Diário Oficial da União, Poder Executivo, Brasília, DF, 05 out. 1988. Disponível em: <http://www.planalto.gov.br/ccivil_03/constituicao/constituicao.htm>. Acesso em: 02 fev. 2017: "Art. 50 Todos são iguais perante a lei, sem distinção de qualquer natureza, garantindo-se aos
} 
URBAN, Renan Lucas Dutra. Decisões técnicas, escolhas morais e democracia: agências reguladoras e deliberação sobre direitos fundamentais. Revista Eletrônica Direito e Política, Programa de PósGraduação Stricto Sensu em Ciência Jurídica da UNIVALI, Itajaí, v.13, n.2, $2^{\circ}$ quadrimestre de 2018. Disponível em: www.univali.br/direitoepolitica - ISSN 1980-7791

duas formas: (a) pela edição de decreto legislativo pelo Congresso Nacional, quando tais atos exorbitarem do poder regulamentar ou dos limites da delegação legislativa, nos termos do artigo 49, inciso V, da Constituição Federal; ${ }^{13}$ ou (b) pela edição de uma lei em sentido formal, de maneira a limitar a competência da agência reguladora para deliberar sobre a questão legislada.

Qualquer mecanismo de controle tem como objetivo principal corrigir os erros contidos nas decisões controladas. Assim, se determinado ato normativo regulatório veicula um erro, espera-se que a revisão judicial ou legislativa seja capaz de eliminá-lo. A objeção dos custos de erro associados à tomada da decisão final pelas agências, dessa maneira, é enfraquecida pela possibilidade de que os atos normativos regulatórios sejam controlados por outras instituições.

A segunda dificuldade relacionada à delegação, porém, decorre exatamente do controle das decisões finais. Trata-se do problema da assimetria de informações, que, no contexto do controle das normas regulatórias, se traduz - como se discutirá a seguir - nas melhores condições epistêmicas das agências para decidir uma questão, em comparação com as dos órgãos controladores.

\section{O PROBLEMA DO CONTROLE DOS ATOS REGULATÓRIOS TECNICAMENTE COMPLEXOS}

Os atos normativos regulatórios envolvem, frequentemente, questões técnicas complexas, isto é, problemas cuja compreensão e solução exigem o domínio de conhecimentos científicos não triviais. As condições das agências reguladoras para decidir tais problemas são garantidas por seus dirigentes e quadros de assessoria,

\footnotetext{
brasileiros e aos estrangeiros residentes no País a inviolabilidade do direito à vida, à liberdade, à igualdade, à segurança e à propriedade, nos termos seguintes: [...] XXXV - a lei não excluirá da apreciação do Poder Judiciário lesão ou ameaça a direito".

${ }^{13}$ Cf. BRASIL. Constituição (1988). Constituição da República Federativa do Brasil de 1988. Diário Oficial da União, Poder Executivo, Brasília, DF, 05 out. 1988. Disponível em: <http://www.planalto.gov.br/ccivil_03/constituicao/constituicao.htm>. Acesso em: 02 fev. 2017: "Art. 49. É da competência exclusiva do Congresso Nacional: [...] V - sustar os atos normativos do Poder Executivo que exorbitem do poder regulamentar ou dos limites de delegação legislativa".
} 
URBAN, Renan Lucas Dutra. Decisões técnicas, escolhas morais e democracia: agências reguladoras e deliberação sobre direitos fundamentais. Revista Eletrônica Direito e Política, Programa de PósGraduação Stricto Sensu em Ciência Jurídica da UNIVALI, Itajaí, v.13, n.2, $2^{\circ}$ quadrimestre de 2018. Disponível em: www.univali.br/direitoepolitica - ISSN 1980-7791

detentores, em tese, de um saber técnico especializado e familiarizados com os assuntos atinentes ao setor regulado. ${ }^{14}$

A complexidade técnica peculiar às normas editadas pelas agências reguladoras suscita a questão das limitações epistêmicas das instituições encarregadas de controlá-las. Ora, se a principal razão para a delegação, como decisão de segunda ordem, são as condições do delegado para formular melhores respostas para certas questões, então subsiste o problema dos custos associados à tomada de decisão pelo delegante, quando este - ou outro órgão, dotado de recursos equivalentes - é incumbido de controlar e revisar as decisões proferidas por aquele.

Na literatura jurídica, é frequente a menção às limitações dos órgãos judiciais para controlar a atividade normativa das agências reguladoras. Tais limitações decorreriam não apenas da falta de conhecimento técnico especializado dos membros do Poder Judiciário, em geral, para decidir as questões relativas à regulação, mas também da escassez de tempo e de recursos financeiros desses órgãos para buscar e processar as informações necessárias para a tomada de decisão.

Há grande discussão, além disso, acerca do impacto das decisões judiciais sobre a política regulatória. Fala-se, nesse contexto, em elevação do risco de incoerência regulatória, produto de decisões judiciais segmentadas e excessivamente intrusivas. Por exemplo, a interferência dos órgãos judiciais na definição do referencial teórico que orienta as medidas regulatórias alça-os à posição de árbitros de querelas entre teorias e/ou métodos científicos, o que redunda em problemas de déficit de legitimidade tanto do ponto de vista da Ciência como do Direito. ${ }^{15}$ Porém, mais do que isso, também se diz que tal intervenção pode prejudicar a coerência regulatória, na medida em que incide sobre uma estratégia

\footnotetext{
14 VERÍSSIMO, Marcos Paulo. Aproximação sistemática ao controle judicial das agências de regulação econômica no Brasil. 265 f. Dissertação (Mestrado em Direito) - Faculdade de Direito, Universidade de São Paulo, São Paulo, 2002. p. 226.

15 SCHUARTZ, Luis Fernando. Interdisciplinaridade e adjudicação: caminhos e descaminhos da ciência do direito. Rio de Janeiro, 2009. p. 12-13. Disponível em: <https://bibliotecadigital.fgv.br/dspace/handle/10438/2174>. Acesso em: 17 jan. 2018.
} 
URBAN, Renan Lucas Dutra. Decisões técnicas, escolhas morais e democracia: agências reguladoras e deliberação sobre direitos fundamentais. Revista Eletrônica Direito e Política, Programa de PósGraduação Stricto Sensu em Ciência Jurídica da UNIVALI, Itajaí, v.13, n.2, $2^{\circ}$ quadrimestre de 2018. Disponível em: www.univali.br/direitoepolitica - ISSN 1980-7791

decisória adotada pela autoridade reguladora como forma de conferir eficiência e racionalidade à sua atuação. ${ }^{16}$

Outra preocupação diz respeito às consequências da atuação judicial para a dinâmica regulatória. As atividades objeto de regulação exigem prestações normativas expeditas, quase imediatas. A lentidão e o formalismo, que tradicionalmente caracterizam os procedimentos judiciais, comprometeriam, dessa maneira, a eficácia das normas regulatórias. Além disso, argumenta-se que a correção ou a redução dos erros associados às decisões normativas das agências reguladoras, por meio da revisão judicial, importa, no limite, a paralisação - ou a "ossificação" - da ação regulatória. Dessa maneira, os ônus impostos por decisões judiciais muito exigentes desencorajariam a produção de normas jurídicas pelas agências, dadas as restrições de tempo e de recursos dessas entidades. ${ }^{17}$

A expertise técnica da burocracia reguladora atua, dessa maneira, como um argumento em favor da adoção de uma postura de deferência pelos órgãos controladores. As agências reguladoras e os órgãos judiciais e legislativos, em razão de suas características específicas, analisam os problemas que thes são submetidos por prismas diversos. Desempenham diferentes funções e perseguem distintos objetivos e, por isso, dispõem de diferentes recursos para lidar com certos problemas. Possuem, em suma, distintas competências, indicativas de suas singulares capacidades institucionais.

Todavia, a ideia de que as agências são mais aptas para resolver os problemas relativos à regulação - subentendida, como visto, na defesa da alocação de ampla competência normativa para esses entes - veicula uma questão empírica que pode ser testada. Marcos Paulo Veríssimo, por exemplo, observa que "[...] as agências não são propriamente e sempre dirigidas por agentes públicos dotados de especial

16 Cf. JORDÃO, Eduardo. Controle judicial de uma administração pública complexa: a experiência estrangeira na adaptação da intensidade do controle. Malheiros: São Paulo, 2016. p. 151-154.

17 Cf., nesse sentido, BREYER, Stephen. Judicial review of questions of law and policy. Administrative Law Review, Chicago, n. 38, p. 391-393, 1986; JORDÃO, Eduardo. Controle judicial de uma administração pública complexa: a experiência estrangeira na adaptação da intensidade do controle. p. 158-163. 
URBAN, Renan Lucas Dutra. Decisões técnicas, escolhas morais e democracia: agências reguladoras e deliberação sobre direitos fundamentais. Revista Eletrônica Direito e Política, Programa de PósGraduação Stricto Sensu em Ciência Jurídica da UNIVALI, Itajaí, v.13, n.2, $2^{\circ}$ quadrimestre de 2018. Disponível em: www.univali.br/direitoepolitica - ISSN 1980-7791

capacitação técnica para as matérias que se colocam para seu exame."18 Pelo contrário - prossegue o autor - , os órgãos de direção das agências tendem a ser ocupados por não especialistas nas matérias técnicas atinentes à regulação, até como forma de garantir algum pluralismo no âmbito dessas entidades. ${ }^{19}$

Em termos gerais, a capacidade de uma instituição para decidir determinada questão é sempre relativa, uma vez que suscetível de ser graduada em função das habilidades e limitações concretas das outras instituições também autorizadas a decidi-la. ${ }^{20}$ No contexto específico do controle dos atos normativos regulatórios, é possível que um órgão controlador reúna condições de formular respostas apropriadas para determinado problema atinente à regulação, em comparação com aquelas sob as quais a agência atua. ${ }^{21} \mathrm{~A}$ decisão sobre a intensidade do controle de uma medida regulatória, nesse sentido, implica uma análise institucional comparativa, isto é, a consideração não apenas da capacidade (concreta) da agência reguladora para resolver as questões técnicas relacionadas à regulação, mas também a consideração da capacidade (concreta) do órgão controlador para resolver as mesmas questões.

É de observar, além disso, que os órgãos controladores, em geral, podem lançar mão de "meios de obtenção de informações" ou de "meios de capacitação", isto é, de ferramentas destinadas à coleta das informações exigidas para a compreensão de problemas técnicos complexos. Os órgãos judiciais, por exemplo, podem se

\footnotetext{
18 VERÍSSIMO, Marcos Paulo. Aproximação sistemática ao controle judicial das agências de regulação econômica no Brasil. p. 225 (grifo do autor).

19 VERÍSSIMO, Marcos Paulo. Aproximação sistemática ao controle judicial das agências de regulação econômica no Brasil. p. 225.

20 No mesmo sentido, cf. BRADY, Alan David Patrick. A structural, institutionally sensitive model of proportionality and deference under the Human Rights Act 1998. $325 \mathrm{f}$. Tese (Doutorado em Filosofia) - The London School of Economics and Political Science, London, 2009. p. 135; LIMA, Rafael Scavone Bellem de. Otimização de princípios, separação dos poderes e segurança jurídica: o conflito entre regra e princípio. 157 f. Dissertação (Mestrado em Direito) Faculdade de Direito, Universidade de São Paulo, São Paulo, 2012. p. 129.

21 Nesse ponto, a ideia de capacidade institucional relativa, aqui adotada como premissa, se aproxima do argumento das capacidades institucionais, na forma como desenvolvido por Cass Sunstein e Adrian Vermeule (cf. SUNSTEIN, Cass. R.; VERMEULE, Adrian. Interpretation and institutions. Michigan Law Review, Worcester, v. 101, p. 885-951, Feb. 2003) e descrito por Diego Werneck Arguelhes e Fernando Leal (cf. ARGUELHES, Diego Werneck; LEAL, Fernando. O argumento das "capacidades institucionais" entre a banalidade, a redundância e o absurdo. Direito, Estado e Sociedade, Rio de Janeiro, n. 38, p. 6-50, jan./jun. 2011).
} 
URBAN, Renan Lucas Dutra. Decisões técnicas, escolhas morais e democracia: agências reguladoras e deliberação sobre direitos fundamentais. Revista Eletrônica Direito e Política, Programa de PósGraduação Stricto Sensu em Ciência Jurídica da UNIVALI, Itajaí, v.13, n.2, $2^{\circ}$ quadrimestre de 2018. Disponível em: www.univali.br/direitoepolitica - ISSN 1980-7791

valer do auxílio de peritos, de maneira que estes Ihes prestem aconselhamento sobre os assuntos técnicos subjacentes à regulação. Nesse particular, Marcos Paulo Veríssimo - admitindo, à luz das normas do Código de Processo Civil brasileiro, o recurso a esse tipo de assessoria técnica - observa que os peritos podem ajudar os juízes "[...] quer no que se refere à verificação passada de determinados acontecimentos, quer no que se refere à formulação de juízos prognósticos, tão comuns em matéria regulatória $[\ldots]^{\prime \prime}{ }^{22}$

Um meio de obtenção de informações que leva em consideração as diferentes expertises ou capacidades das instituições é o chamado "diálogo institucional". No contexto do controle judicial dos atos normativos regulatórios, tal ferramenta de capacitação pode levar à tomada de melhores decisões, por duas razões fundamentais. Em primeiro lugar, porque proporciona aos órgãos do Poder Judiciário a obtenção, junto aos quadros técnicos da agência reguladora que expediu $o$ ato controlado, de informações e dados específicos, aos quais dificilmente teriam acesso. Em segundo lugar, porque enseja que os órgãos judiciais percebam as diferentes perspectivas ou pontos de observação existentes sobre as questões que terão de ser por eles enfrentadas. A interação deliberativa entre as instituições no contexto do controle dos atos normativos regulatórios, portanto, tende a elevar a qualidade das decisões, já que permite que os órgãos judiciais tenham um conhecimento mais amplo e diversificado sobre o assunto técnico de que trata o ato normativo regulatório objeto de controle.

De resto, é importante salientar que os atos normativos regulatórios não têm, todos eles, o mesmo grau de complexidade, nem decidem apenas problemas técnicos. Como observa Adrian Vermeule, o processo normativo regulatório pressupõe, basicamente, dois estágios, um relacionado a questões sobre fatos e outro relativo a questões sobre valores. ${ }^{23}$ As questões sobre fatos envolvem a determinação de relações de causalidade e a realização de predições (prognósticos). Demandam, assim, o recurso às disciplinas científicas pertinentes,

\footnotetext{
22 VERÍSSIMO, Marcos Paulo. Aproximação sistemática ao controle judicial das agências de regulação econômica no Brasil. p. 228 (grifo do autor).

${ }^{23}$ VERMEULE, Adrian. The parliament of the experts. Duke Law Journal, Durham, n. 8, v. 58, p. 2236, May 2009.
} 
URBAN, Renan Lucas Dutra. Decisões técnicas, escolhas morais e democracia: agências reguladoras e deliberação sobre direitos fundamentais. Revista Eletrônica Direito e Política, Programa de PósGraduação Stricto Sensu em Ciência Jurídica da UNIVALI, Itajaí, v.13, n.2, $2^{\circ}$ quadrimestre de 2018. Disponível em: www.univali.br/direitoepolitica - ISSN 1980-7791

fornecedoras das justificativas que suportam a pretensão de veracidade das proposições teóricas e empíricas relacionadas a tais questões. Já as questões sobre valores envolvem escolhas morais, e se relacionam à necessidade de que os agentes reguladores, tendo em vista a realização de determinados fins, procedam a uma ponderação entre os princípios ou valores concorrentes. Desse modo, a análise institucional comparativa, que orienta a decisão sobre a intensidade do controle, implica não apenas avaliar a capacidade das instituições envolvidas agência reguladora e órgão controlador - para lidar com as questões factuais decididas pela norma regulatória, mas também a capacidade dessas instituições para lidar com as questões valorativas solucionados pela norma. Ou seja, ela importa examinar os recursos e os limites concretos das instituições para apreciar tanto os problemas de perícia quanto os de moralidade política subjacentes ao ato controlado. ${ }^{24}$

\section{A BUROCRACIA REgULADORA COMO FÓRUM DE DELIBERAÇÃo SOBRE DIREITOS FUNDAMENTAIS}

A constatação, de certa forma trivial, de que a burocracia reguladora também profere decisões políticas, resolvendo questões morais, suscita um terceiro problema relativo à delegação: o da legitimidade da transferência do ônus da decisão final. Nesse ponto, é frequente a menção a uma ilegitimidade da atividade normativa das agências, seja pela ausência de investidura popular de seus dirigentes, seja por uma vedação genérica, no texto constitucional, de delegação legislativa, seja, ainda, por uma incompatibilidade entre o desempenho de função normativa por tais entidades e a doutrina da separação dos poderes. ${ }^{25}$

\footnotetext{
24 Referimo-nos, aqui, a duas funções morais das regras jurídicas, em geral: a de coordenação, correspondente à solução de problemas de incerteza e desacordo sobre questões de moralidade política; e a de perícia, correspondente à solução de problemas de incerteza e desacordo sobre questões factuais. Cf., no ponto, ALEXANDER, Larry. "With me, It's all er nuthin'": formalism in law and morality. University of Chicago Law Review, Chicago, n. 66, p. 531-536, 1999.

25 A propósito dos argumentos contrários à delegação legislativa, cf. VEIGA DA ROCHA, Jean Paul Cabral. A capacidade normativa de conjuntura no direito econômico: o déficit democrático da regulação financeira. p. 12-17; MATTOS, Paulo Todescan Lessa. O novo Estado regulador no Brasil: eficiência e legitimidade. p. 206-208.
} 
URBAN, Renan Lucas Dutra. Decisões técnicas, escolhas morais e democracia: agências reguladoras e deliberação sobre direitos fundamentais. Revista Eletrônica Direito e Política, Programa de PósGraduação Stricto Sensu em Ciência Jurídica da UNIVALI, Itajaí, v.13, n.2, $2^{\circ}$ quadrimestre de 2018. Disponível em: www.univali.br/direitoepolitica - ISSN 1980-7791

À semelhança da discussão sobre a legitimidade do controle judicial de constitucionalidade, ${ }^{26}$ o problema da legitimidade da delegação de competência normativa às agências reguladoras é geralmente pensado em termos binários: ou bem se considera que a atividade normativa regulatória é democrática ou bem se considera que ela é antidemocrática. A caracterização do ato de delegação como uma decisão de segunda ordem, no entanto, permite visualizar tal problema como uma questão de grau. Se, como assinalado, a delegação visa à produção de melhores decisões, mediante transferência do ônus de solucionar determinados problemas para um terceiro, idealmente mais bem capacitado para lidar com tais problemas, então é possível considerar que a legitimidade da delegação está também condicionada à qualidade das decisões finais. Nesse sentido, as agências reguladoras, que recebem a delegação do Poder Legislativo, podem ser consideradas tanto mais legítimas para editar normas jurídicas - e, por conseguinte, para promover e restringir direitos dos administrados - quanto maior for a qualidade de suas decisões.

Como observa Conrado Hübner Mendes, as variáveis de legitimidade de uma democracia não se esgotam no procedimento (input), abrangendo também os resultados (output). Ou seja: o princípio democrático não se resume à estrutura formal de poder, à divisão de competências entre as instituições. A caracterização de um regime como democrático depende também dos resultados substantivos por elas alcançados. Diante disso, parece ser natural que

[...] a substância subordine, em algumas circunstâncias, o procedimento, ou seja, que a instituição que tenha alcançado a resposta mais compatível com um critério substantivo de legitimidade tenha boas razões para prevalecer independentemente de seu pedigree (subvertendo a estrutura formal). ${ }^{27}$

26 Sobre as concepções teóricas sobre a legitimidade democrática do controle judicial de constitucionalidade - divididas entre aquelas inclinadas por uma "supremacia legislativa" e aqueloutras inclinadas por uma "supremacia judicial" -, cf. MENDES, Conrado Hübner. Deliberação, separação dos poderes e direitos fundamentais. 267 f. Tese (Doutorado em Ciência Política) Faculdade de Filosofia, Letras e Ciências Humanas, Universidade de São Paulo, São Paulo, 2008. p. 61-103.

27 MENDES, Conrado Hübner. Deliberação, separação dos poderes e direitos fundamentais. p. 201. 
URBAN, Renan Lucas Dutra. Decisões técnicas, escolhas morais e democracia: agências reguladoras e deliberação sobre direitos fundamentais. Revista Eletrônica Direito e Política, Programa de PósGraduação Stricto Sensu em Ciência Jurídica da UNIVALI, Itajaí, v.13, n.2, $2^{\circ}$ quadrimestre de 2018. Disponível em: www.univali.br/direitoepolitica - ISSN 1980-7791

Nesse sentido, é possível defender que a legitimidade democrática das agências reguladoras para deliberar sobre direitos fundamentais varia conforme 0 desempenho deliberativo alcançado por essas entidades. Em outras palavras, é possível defender que, quanto maior for o grau de qualidade ou de eficiência - em termos de redução dos custos de erro e de decisão - das decisões tomadas pelas agências reguladoras, maior será o grau de legitimidade de sua atividade normativa.

A ordem jurídica institui alguns mecanismos de controle democrático da atividade normativa da burocracia reguladora, os quais atendem, de certa forma, a essa exigência de maior eficiência na tomada de decisão. Os atos normativos que regem a ANATEL, por exemplo, preveem dois mecanismos clássicos de participação democrática: a consulta pública e a audiência pública. ${ }^{28} \mathrm{~A}$ consulta pública consiste em procedimento de submissão, à opinião pública, de minutas de atos normativos. Sua finalidade é permitir que, dentro de determinado prazo, todos os eventuais interessados ofereçam críticas ou sugestões, solicitem informações ou peçam esclarecimentos a respeito do ato normativo a ser editado. Já as audiências públicas consistem em sessões abertas a cidadãos, associações e demais interessados, nas quais são esclarecidos e debatidos temas passíveis de deliberação, como os relativos a processos administrativos decisórios e a projetos de atos normativos. ${ }^{29}$ Sua finalidade é permitir que indivíduos ou determinados

\footnotetext{
${ }^{28}$ As consultas públicas estão previstas no artigo 42 da Lei Geral de Telecomunicações. Cf. BRASIL. Lei n. 9.472, de 16 de julho de 1997. Dispõe sobre a organização dos serviços de telecomunicações, a criação e funcionamento de um órgão regulador e outros aspectos institucionais, nos termos da Emenda Constitucional n. 8, de 1995. Diário Oficial da União, Poder Executivo, Brasília, DF, 17 jul. 2007. Disponível em: <http://www.planalto.gov.br/ccivil_03/leis/I9472.htm>. Acesso em: 05 fev. 2017: "Art. 42. As minutas de atos normativos serão submetidas à consulta pública, formalizada por publicação no Diário Oficial da União, devendo as críticas e sugestões merecer exame e permanecer à disposição do público na Biblioteca." Já as audiências públicas estão disciplinadas nos artigos 56 a 58 do Regimento Interno da ANATEL. Cf. AGÊNCIA NACIONAL DE TELECOMUNICAÇÕES. Aprova o Regimento Interno da ANATEL. Resolução no 612, de 29 de abril de 2013. Diário Oficial da União, Poder Executivo, Brasília, DF, 02 maio 2013. Disponível em: <http://pesquisa.in.gov.br/imprensa/jsp/visualiza/index.jsp?jornal=1\&pagina $=68 \&$ data $=02 / 05 / 20$ 13>. Acesso em: 05 fev. 2017: "Art. 56. A Audiência Pública destina-se a debater ou apresentar, oralmente, matéria de interesse relevante, definida pelo Conselho Diretor."
}

29 Cf. BINENBOJM, Gustavo. Uma teoria do direito administrativo. Rio de Janeiro: Renovar, 2008. p. 296. 
URBAN, Renan Lucas Dutra. Decisões técnicas, escolhas morais e democracia: agências reguladoras e deliberação sobre direitos fundamentais. Revista Eletrônica Direito e Política, Programa de PósGraduação Stricto Sensu em Ciência Jurídica da UNIVALI, Itajaí, v.13, n.2, $2^{\circ}$ quadrimestre de 2018. Disponível em: www.univali.br/direitoepolitica - ISSN 1980-7791

grupos manifestem seus interesses e exponham suas ideias, de modo que possam influir diretamente no conteúdo da regulação.

A participação dos cidadãos nos processos regulatórios normalmente auxilia os gestores das agências a avaliar a sintonia das políticas setoriais com 0 planejamento macroeconômico encampado pelo governo. Ela ajuda a prevenir, assim, a chamada "visão de túnel", fenômeno identificado à situação em que um gestor público, preso à sua expertise e às especificidades do setor econômico no qual atua, perde a capacidade de avaliar aspectos estratégicos e macroeconômicos das políticas setoriais por ele implementadas. ${ }^{30}$ Além disso, a abertura dos procedimentos decisórios à cidadania permite que sejam conhecidos e discutidos os diversos interesses subjacentes às normas expedidas pelas agências. Ela se presta a combater, dessa forma, a chamada "captura", fenômeno caracterizado pela cooptação das agências reguladoras pelos agentes econômicos do setor regulado, os quais passam a controlar a ação normativa de tais entidades de maneira que seus interesses particulares sejam atendidos, em detrimento do interesse público. ${ }^{31}$

Como se percebe, a participação popular no processo regulatório, na medida em que oferece mecanismos de fiscalização e controle das entidades responsáveis pela formulação e execução das políticas setoriais, tende a coibir práticas de favorecimento a segmentos influentes da atividade econômica regulada, evitando a sobreposição dos interesses particulares ao interesse público. Além disso, a participação da sociedade no processo regulador, dado o fato de que evidencia as demandas, pautas e reivindicações do setor regulado, importa o conhecimento, pelas agências reguladoras, dos mais diversos interesses subjacentes à regulação, possibilitando que elas resolvam problemas jurídicos com maior probabilidade de acerto. $^{32}$

\footnotetext{
30 Cf. BINENBOJM, Gustavo. Uma teoria do direito administrativo. p. 304-305; JUSTEN FILHO, Marçal. $\mathbf{O}$ direito das agências reguladoras independentes. São Paulo: Dialética, 2002. p. 372.

31 Cf., sobre o fenômeno da captura regulatória, STIGLER, George J. A teoria da regulação econômica. In: MATTOS, Paulo Todescan Lessa (coord.). Regulação econômica e democracia: 0 debate norte-americano. São Paulo: Ed. 34.
}

32 Cf., nesse sentido, BACELLAR FILHO, Romeu Felipe. O poder normativo dos entes reguladores e a participação dos cidadãos nesta atividade. Serviços públicos e direitos 
URBAN, Renan Lucas Dutra. Decisões técnicas, escolhas morais e democracia: agências reguladoras e deliberação sobre direitos fundamentais. Revista Eletrônica Direito e Política, Programa de PósGraduação Stricto Sensu em Ciência Jurídica da UNIVALI, Itajaí, v.13, n.2, $2^{\circ}$ quadrimestre de 2018. Disponível em: www.univali.br/direitoepolitica - ISSN 1980-7791

Os mecanismos de controle democrático - como as consultas públicas e as audiências públicas -, portanto, fomentam a transparência e favorecem a diminuição dos custos de erro associados à tomada de decisão pelos entes de regulação. Nesse sentido, pode-se dizer que a efetivação de tais mecanismos tende a elevar o desempenho deliberativo das agências, aumentando o grau de legitimidade de tais autarquias para editar normas jurídicas e fazer escolhas morais.

Outro mecanismo que pode conferir maior eficiência e legitimidade à atividade normativa da burocracia reguladora é o diálogo institucional. Como já salientado, a interação deliberativa entre as instituições é uma estratégia decisória (ou meio de capacitação) que permite a obtenção, pelos tomadores de decisão, de informações às quais eles dificilmente teriam acesso, em função de uma falta de conhecimentos específicos - expertise - sobre determinada matéria. Na medida em que propicia um aprendizado recíproco, pode-se dizer que o diálogo institucional veicula um efeito epistêmico positivo, relacionado à redução dos custos de erro associados à tomada de decisão. ${ }^{33}$

A ideia de diálogo entre a burocracia reguladora e os órgãos judiciais vincula-se a uma concepção deliberativa de Administração Pública, que rejeita tanto uma visão puramente tecnocrática quanto uma visão política sobre a regulação. ${ }^{34}$ No âmbito do controle judicial dos atos normativos regulatórios, o diálogo implica o intercâmbio, entre as agências reguladoras e o Poder Judiciário, não apenas dos argumentos empíricos e teóricos relativos aos aspectos factuais da medida controlada, como também dos argumentos jurídicos e políticos concernentes às questões valorativas solucionadas por essa medida. Tendencialmente, assim, o diálogo mitiga as dificuldades decorrentes de uma eventual falta de expertise das agências para resolver problemas de moralidade política, diminuindo a

fundamentais: os desafios da regulação na experiência brasileira. Revista de Direito Administrativo, Rio de Janeiro, v. 230, out./dez. 2002. p. 161-162.

33 Acerca do potencial epistêmico do diálogo institucional, cf. MENDES, Conrado Hübner. Deliberação, separação dos poderes e direitos fundamentais. p. 218 e ss.

34 Cf., sobre a concepção deliberativa de Administração Pública, SUNSTEIN, Cass R. O constitucionalismo após o The New Deal. In: MATTOS, Paulo Todescan Lessa (coord.). Regulação econômica e democracia: o debate norte-americano. São Paulo: Ed. 34, 2004. p. 170. 
URBAN, Renan Lucas Dutra. Decisões técnicas, escolhas morais e democracia: agências reguladoras e deliberação sobre direitos fundamentais. Revista Eletrônica Direito e Política, Programa de PósGraduação Stricto Sensu em Ciência Jurídica da UNIVALI, Itajaí, v.13, n.2, $2^{\circ}$ quadrimestre de 2018. Disponível em: www.univali.br/direitoepolitica - ISSN 1980-7791

probabilidade de que tais entidades cometam erros ao deliberar sobre direitos fundamentais.

\section{CONSIDERAÇÕES FINAIS}

As agências reguladoras não possuem a palavra final sobre as matérias relativas à delegação. Os atos normativos regulatórios, como atos administrativos, sujeitam-se ao exame de legalidade realizado pelo Poder Judiciário. Além disso, a atribuição de competência normativa a essas autarquias não implica abdicação, pelo Poder Legislativo, da responsabilidade de deliberar sobre as matérias atinentes à delegação. As normas editadas pelas agências, desse modo, também se submetem aos mecanismos legislativos de controle e revisão dos atos normativos.

A atribuição de competência normativa às agências reguladoras visa ao oferecimento das melhores respostas para os problemas relativos à disciplina de setores econômicos e de serviços de relevante interesse social. A transferência do ônus de fazer escolhas morais para agentes não eleitos, no entanto, suscita o problema da legitimidade democrática. Neste trabalho, defende-se a ideia de que as agências reguladoras possuem legitimidade para exercer uma capacidade normativa de conjuntura desde que os atos por elas expedidos atendam a determinado parâmetro de eficiência. Ou seja: quanto menores forem os custos de erro e de decisão associados à atividade normativa das agências, maior será grau de legitimidade democrática dessas entidades.

\section{REFERÊNCIAS DAS FONTES CITADAS}

. Lei n. 9.472, de 16 de julho de 1997. Dispõe sobre a organização dos serviços de telecomunicações, a criação e funcionamento de um órgão regulador e outros aspectos institucionais, nos termos da Emenda Constitucional n. 8, de 1995. Diário Oficial da União, Poder Executivo, Brasília, DF, 17 jul. 2007. Disponível em: <http://www.planalto.gov.br/ccivil_03/leis/l9472.htm>. Acesso em: 05 fev. 2017.

Must formalism be defended empirically? The University of Chicago

Law Review, Chicago, v. 66, n. 3, p. 636-670, Sum. 1999. 
URBAN, Renan Lucas Dutra. Decisões técnicas, escolhas morais e democracia: agências reguladoras e deliberação sobre direitos fundamentais. Revista Eletrônica Direito e Política, Programa de PósGraduação Stricto Sensu em Ciência Jurídica da UNIVALI, Itajaí, v.13, n.2, $2^{\circ}$ quadrimestre de 2018. Disponível em: www.univali.br/direitoepolitica - ISSN 1980-7791

O constitucionalismo após o The New Deal. In: MATTOS, Paulo Todescan Lessa (coord.). Regulação econômica e democracia: o debate norteamericano. São Paulo: Ed. 34, 2004.

.; VERMEULE, Adrian. Interpretation and institutions. Michigan Law

Review, Worcester, v. 101, p. 885-951, Feb. 2003.

AGÊNCIA NACIONAL DE TELECOMUNICAÇÕES. Aprova o Regimento Interno da ANATEL. Resolução no 612, de 29 de abril de 2013. Diário Oficial da União, Poder Executivo, Brasília, DF, 02 maio 2013. Disponível em:

<http://pesquisa.in.gov.br/imprensa/jsp/visualiza/index.jsp?jornal=1\&pagina=6 8\&data=02/05/2013 > . Acesso em: 05 fev. 2017.

ALEXANDER, Larry. "With me, It's all er nuthin'": formalism in law and morality. University of Chicago Law Review, Chicago, n. 66, p. 530-565, 1999.

ARGUELHES, Diego Werneck; LEAL, Fernando. O argumento das "capacidades institucionais" entre a banalidade, a redundância e o absurdo. Direito, Estado e Sociedade, Rio de Janeiro, n. 38, p. 6-50, jan./jun. 2011.

BACELLAR FILHO, Romeu Felipe. O poder normativo dos entes reguladores e a participação dos cidadãos nesta atividade. Serviços públicos e direitos fundamentais: os desafios da regulação na experiência brasileira. Revista de Direito Administrativo, Rio de Janeiro, v. 230, p. 153-162, out./dez. 2002.

BINENBOJM, Gustavo. Uma teoria do direito administrativo. Rio de Janeiro: Renovar, 2008.

BRADY, Alan David Patrick. A structural, institutionally sensitive model of proportionality and deference under the Human Rights Act 1998. $325 \mathrm{f}$. Tese (Doutorado em Filosofia) - The London School of Economics and Political Science, London, 2009.

BRASIL. Constituição (1988). Constituição da República Federativa do Brasil de 1988. Diário Oficial da União, Poder Executivo, Brasília, DF, 05 out. 1988.

Disponível em:

<http://www.planalto.gov.br/ccivil_03/constituicao/constituicao.htm>. Acesso em: 02 fev. 2017.

BREYER, Stephen. Judicial review of questions of law and policy. Administrative Law Review, Chicago, n. 38, p. 363-398, 1986.

JORDÃO, Eduardo. Controle judicial de uma administração pública complexa: a experiência estrangeira na adaptação da intensidade do controle. Malheiros: São Paulo, 2016.

LIMA, Rafael Scavone Bellem de. Otimização de princípios, separação dos poderes e segurança jurídica: o conflito entre regra e princípio. $157 \mathrm{f}$. Dissertação (Mestrado em Direito) - Faculdade de Direito, Universidade de São Paulo, São Paulo, 2012. 
URBAN, Renan Lucas Dutra. Decisões técnicas, escolhas morais e democracia: agências reguladoras e deliberação sobre direitos fundamentais. Revista Eletrônica Direito e Política, Programa de PósGraduação Stricto Sensu em Ciência Jurídica da UNIVALI, Itajaí, v.13, n.2, $2^{\circ}$ quadrimestre de 2018. Disponível em: www.univali.br/direitoepolitica - ISSN 1980-7791

LOPES, Othon de Azevedo. Princípios jurídicos e regulação. $251 \mathrm{f}$. Tese (Doutorado em Direito) - Pontifícia Universidade Católica de São Paulo, São Paulo, 2011.

MATTOS, Paulo Todescan Lessa. O novo Estado regulador no Brasil: eficiência e legitimidade. São Paulo: Singular, 2006.

MENDES, Conrado Hübner. Deliberação, separação dos poderes e direitos fundamentais. 267 f. Tese (Doutorado em Ciência Política) - Faculdade de Filosofia, Letras e Ciências Humanas, Universidade de São Paulo, São Paulo, 2008.

PRADO, Mariana Mota. Agências reguladoras, independência e desenho institucional. São Paulo: Bovespa, Duke Energy, Ipiranga e Instituto Tendências, 2005.

SCHUARTZ, Luis Fernando. Interdisciplinaridade e adjudicação: caminhos e descaminhos da ciência do direito. Rio de Janeiro, 2009. Disponível em: <https://bibliotecadigital.fgv.br/dspace/handle/10438/2174>. Acesso em: 17 jan. 2018.

STIGLER, George J. A teoria da regulação econômica. In: MATTOS, Paulo Todescan Lessa (coord.). Regulação econômica e democracia: o debate norte-americano. São Paulo: Ed. 34.

SUNDFELD, Carlos Ari. Introdução às agências reguladoras. In: (coord). Direito administrativo econômico. São Paulo: Malheiros, 2002.

SUNSTEIN, Cass R.; ULLMANN-MARGALIT, Edna. Second order decisions. John M. Olin Law \& Economics Working Paper, Chicago, n. 57, p. 1-43, 1998.

VEIGA DA ROCHA, Jean Paul Cabral. A capacidade normativa de conjuntura no direito econômico: o déficit democrático da regulação financeira. $204 \mathrm{f}$. Tese (Doutorado em Direito) - Faculdade de Direito, Universidade de São Paulo, São Paulo, 2004.

VERÍSSIMO, Marcos Paulo. Aproximação sistemática ao controle judicial das agências de regulação econômica no Brasil. 265 f. Dissertação (Mestrado em Direito) - Faculdade de Direito, Universidade de São Paulo, São Paulo, 2002.

VERMEULE, Adrian. The parliament of the experts. Duke Law Journal, Durham, n. 8, v. 58, p. 2231-2275, May 2009.

Recebido em: 29/03/2018

Aprovado em: 26/06/2018 